\title{
Die opkoms van die menseregte-ideologie en enkele begeleidingsimplikasies daarvan
}

\author{
E.J. van Niekerk \\ Departement Historiese Opvoedkunde \\ Universiteit van Suid-Afrika \\ PRETORIA
}

\begin{abstract}
The rise of the human rights ideology and its implications for accompaniment

Since the Renaissance several developments have contributed to the rise and the eventual consolidation of the currenily popular human rights ideology. In this article three of these developments are discussed. namely the advent of a developed societal dispensation, the advent of a globalistic societal dispensation and the advent of a secularistic societal dispensation. from this historical investigation several general implications of the human rights ideology for the South African educational context are indicated. inferred.
\end{abstract}

\section{Inleiding}

Pretorius (1985:28) definieer ideologie soos volg:

\begin{abstract}
'n Ideologie is 'n lewens- en wêreldbeskouing wat op 'n dinamiese wyse deur sy navolgers nagestreef, geleef en geregverdig word ten einde maatskaplike, politieke, ekonomiese en ander veranderinge te bewerkstellig sodat die Idee (doel) van die Ideologie op sy suiwerste deur woord en daad binne 'n bepaalde struktuur verwesenlik kan word.
\end{abstract}

In die lig hiervan, en van talle ander definisies van die begrip ideologie, kwalifiseer menseregte soos voorgestaan deur die hedendaagse wêreld inderdaad vir ideologiestatus: menseregte word onderlê deur 'n sekulêr-humanistiese lewens- en wêreldbeskoulike grondinstelling (vgl. par 2.3), en dit is en word steeds deur die aanhangers daarvan aktief bevorder tot die wêreld se eerste globale ideologie aan die hand waarvan gepoog word om menslike verhoudinge in die wêreldsamelewing te reguleer (vgl. par 2.2). Die menseregte-ideologie oefen 'n invloed op talle samelewingsterreine uit. Ook op die onderwys oefen dit reeds 'n groot invloed tuit, soos duidelik blyk uit gebeure op onderwysgebied in Suid-Afrika 
Die menseregte-ideologie geniet sedert die inwerkingtreding van die tussentydse grondwet op 27 April 1994 hier te lande amptelike erkenning. Suid-Afrika se Handves van Regte is in hoofstuk 3 van die Grondwet van die Republiek van Suid-Afrika, No. 200 van 1993 vervat. Die onderwys word hierdeur geraak aangesien sekere artikels in die Handves van Regte direk na die onderwys verwys en ander indirek daarop betrekking het (Visser \& Potgieter, 1994). Die verwagting word voorts deur die onderwysowerhede gekoester dat die hele etos van die onderwys, en meer spesifiek die etos van elke skool, deur die menseregte-kultuur deursuur sal word (RSA, 1995:39-47). In die lig hiervan ontstaan die vraag wat die begeleidingsimplikasies van die menseregte-ideologie is. Ten einde te poog om hierdie vraag in breë trekke te probeer beantwoord moet die historiese konteks waaruit die menseregte-ideologie voortspruit, ondersoek word.

Eietydse verskynsels, soos die hedendaagse menseregte-ideologie, kan slegs behoorlik verstaan word binne die konteks van die historiese omstandighede waaruit dit voortgespruit het. In hierdie verband is verskeie ontwikkelinge wat sedert die Renaissance meegewerk het tot die opkoms en bestendiging van die menseregte-ideologie van belang. Die belangrikste drie van hierdie ontwikkelinge word vanweë hul relevansie vir die tema van hierdie artikel in oënskou geneem, te wete:

- die opkoms van 'n ontwikkelde samelewingsbestel

- die opkoms van 'n globalistiese samelewingsbestel

- die opkoms van 'n gesekulariseerde samelewingsbestel

Eerstens word gevolglik ingegaan op die historiese konteks van die menseregteideologie, waarna aandag gegee sal word aan enkele begeleidingsimplikasies daarvan.

\section{Sleutelfaktore in die opkoms van die menseregte-ideologie}

\subsection{Die opkoms van 'n ontwikkelde samelewingsbestel}

Die opkoms van die ontwikkelde samelewingsbestel, wat op grond van die mens se wetenskaplike en tegnologiese vernuf opgebou is, lê ten grondslag aan die menseregte-ideologie. Die opkoms van hierdie samelewingsbestel onderlê ook die globaliserings- en sekulariseringsproses wat die moderne tydperk kemmerk en wat ook 'n bydrae gelewer het tot die opkoms van die menseregte-ideologie. Daarom word dit eerste bespreek.

Tydens die Renaissance vind 'n intellektuele revolusie in Europa plaas. Nuwe ontdekkings op die gebied van die natuurwetenskap lê die grondslag vir die 
opkoms van 'n ontwikkelde samelewingsvorm. Hierdie samelewing begin duidelik vorm aanneem na die Industriële Revolusie wat sedert ongeveer 1750 in Europa plaasgevind het. Europa word egter reeds voor hierdie gebeurtenis as't ware op ' $n$ intellektuele gereedheidsgrondslag geplaas vir die oorgang vanaf 'n agrariese na 'n industriële beskawingsvorm deur denkers soos onder meer Bacon (1561-1626), Comenius (1592-1670), Descartes (1596-1650) en Locke (16321704). Die voorafgaande ontwikkelinge en die epogale wending na 'n nuwe beskawingsvorn het ' $n$ invloed op alle samelewingsterreine gehad. Net soos wat die natuurwetenskap die mens van die heerskappy van die natuurkragte moes bevry, só het die verwagting ontstaan dat ontwikkeling op die sosiaal-politieke gebied ook sou lei tot die bevryding van die onderworpenheid van die verlede (Van Niekerk, 1992:136-145; Wronka, 1992:60; Laqueur \& Rubin, 1979:3-5).

Die grondliggende voorveronderslelling waarop die modernisme bou, naamlik dié van evoluerende vooruitgang op grond van die mens se wetenskaplike en tegnologiese vermoëns, het ook in die modernistiesc ideologieë neerslag gevind. Só gesien moet ook die menseregte-ideologie - wat in die na-Renaissance tydperk, maar veral rondom die Industrièle Revolusie, sterk op die voorgrond tree - in postınodernistiese taal as een van die master narratives van die modemisme getipeer word. Die verskuilde bedoeling en werking van hierdie ideologie was onder meer om soos $\mathrm{cn}$ in samehang met verskeie ander moderne ideologieë soos die sosialisme, demokrasie en nasionalisme mee te werk tot die daarstelling van die ideale sosiaal-politieke strukture wat moes meehelp tot die verwerkliking van 'n aardse utopie/optinale lewensomstandighede. As een van die verworwenhede van die moderne tyd geniet die menseregte-ideologie tans steeds onverpoos aanhang; dit ten spyte van die terugslae wat die modemistiese vooruitgangsgeloof in die twintigste eeu ondervind, onder meer as gevolg van postmodernistiese kritiek teen die kontinuiteitsmodel van historiese vooruitgang as geskiedenismodel van die moderne era (vgl. Haüsermann, 1988; Van Niekerk, 1992:133-320; Lyotard, 1987:93-94, 108-109).

Die veranderinge op intellektuele gebied sedert die Renaissance asook die mens se inlywing by die nuwe industriële beskawingsvorm sedert die Industriële Revolusie het 'n definitiewe neerslag op die Westerse mens se lewens- en wêreldbeskouing gehad en het ook 'n veranderde mensbeskouing teweeggebring. In die agrariese beskawing het die mens grootliks in afhanklikheid van die natuur en goddelike wette gelcef. Die moderne, industriële beskawing het die mens skynbaar uit hierdie afhanklikheidsposisie ontvoog en van die mens sy eie lotsbeskikker gemaak. Hierdie veranderde siening van homself bring teweeg dat die mens voorts poog on inenslike verhoudinge vanuit 'n menslike waardesisteem, soos vervat in die ideologie van menseregte, te reguleer ( $\mathrm{vgl}$. Haüsernann, 1988:130; De Villiers et al., 1992). 
Die opkoms van die menseregte-ideologie en enkele begeleidingsimplikasies daarvan

Die ontvoogding uit sy aflanklikheidsposisie het die mens se bestaan egter nie noodwendig gladder laat verloop nie. Die moderne beskawing waarin die verklaring en beheersing van die werklikheid met behulp van die wetenskap en tegniek sentraal staan, sou ook die noodsaak bring om menslike gedrag te reguleer vanweë die nuwe potensiaal tot uitbuiting en selfvernietiging wat daarmee gepaard gegaan het. Die ontwikkelde, moderne beskawing noodsaak skynbaar die globalistiese menseregte-ideologie om veral twee redes: eerstens omdat die individu, gesin en familie minder ekonomies selfversorgend is as wat in 'n agrariese beskawingsvorm die geval was, en gevolglik makliker aan uitbuiting blootgestel kan word (Wronka, 1992:75; Iwe, 1986:119); tweedens omdat die ontwikkelde beskawing só ver ontwikkel het dat hy ook die vermoë ontwikkel het om homself te vemietig. Die nuwe beskawingsvorm het inderdaad 'n skrikwekkende potensiaal tot selfvernietiging. Dink maar aan die getalle betrokke by die menseslagtings van hierdie eeu teen die agtergrond van die verdere vernietigingspotensiaal wat die splitsing van die atoomkem daarstel (Van Niekerk, 1992:148-150; Levin, 1988:42). Die ontleding van 'n aantal menseregte-handveste dui daarop dat hierdie realiteit met die menseregte-ideologie in verband gebring moet word (vgl. De Villiers et al., 1992).

Die menseregte-ideologie, wat histories aan die ontwikkelde beskawing gekoppel kan word, het uiteindelik so ontwikkel dat dit 'n aanklag teen die imperialisme van hierdie beskawing geword het. Die menseregte-ideologie is in die verlede en word vandag steeds baie effektief deur die voormalige kolonies teen die ontwikkelde wêreld aangewend. Deur onder meer op die skuldgevoel van die Weste oor sy imperiale verlede in te speel word ontwikkelingshulp makliker uit die Weste verkry. In sy verhouding tot die ontwikkelde wêreld toon veral Afrika blyke van 'n aandrang op ontwikkeling en ontwikkelingshulp as mensereg. Westerlinge is skynbaar steeds so verslaaf aan die gedagte van evoluerende ontwikkeling, vooruitgang en die gelykheidsfilosofie dat dit vir hul moeilik is om te aanvaar dat nie almal oor die nodige beskawingsagtergrond beskik om produktief van ontwikkelingshulp gebruik te maak nie. In die Weste vervul die menseregte-ideologie as't ware die funksie van 'n sekulêre, burgerlike godsdiens (vgl. Potgieter, 1989) en daarom is die Westerse verbondenheid aan dié ideologie en gedagtes wat daamee saamhang, soos die verskaffing van ontwikkelingshulp, verstaanbaar. Skynbaar bestaan daar in die wêreld 'n baie sterk opvatting dat die ganse mensdom op 'n gelyke basis behoort te deel in die voordele wat die ontwikkelde beskawingsvorm gebring het. In die mellseregte-ideologie word hierdie gedagte onderskraag (Van Niekerk, 1992:220-225, 233-238; Van den Berg, 1991).

Uit die voorgaande blyk dat die menseregte-ideologie uit die ontwikkelde beskawingsverband voortgekom het en dat ook die ontwikkelende wêreld reeds 
daarby betrek is. In die volgende paragraaf word aangetoon hoe dit gekom het dat die hele wêreld by hierdie ideologie betrek is.

\subsection{Die opkoms van 'n globalistiese samelewingsbestel}

Die opkoms van die globalistiese samelewingsbestel as uitvloeisel van die moderne projek dien as moontlikheidsvoorwaarde vir die opkoms van die menseregte-ideologie as 'n globalistiese waardesisteem. Soos in die vorige paragraaf aangetoon is, onderlê die moderne wetenskap en tegnologie die opkoms van 'n ontwikkelde samelewingsbestel. Die moderne wetenskap en tegnologie onderlê ook die ontwikkeling van hierdie bestel tot 'n globalistiese bestel. In hierdie verband het die moderne telekommunikasie- en vervoenniddele 'n groot bydrae gelewer on die wêreld in figuurlike sin klein te maak. Die menseregteideologie verkry in die twintigste eeu soveel prominensie omdat die globalisme duidelik in hierdie eeu manifesteer (Van Niekerk, 1992:136-145). Internasionale menseregte kan inderdaad as die wêreld se eerste universele of globale ideologie beskou word (Weissbrodt, 1988:1). Die verband tussen die globalisme en die menseregte-ideologie word deur verskeie skrywers beklemtoon (Lynch, 1989:72; King, 1992:229-230; Iwe, 1986:127-128; Davies, 1988:1, 38-39, 111, 131, 138). In die volgende aanhaling kom hierdie verband duidelik na vore: "Human rights exist as ideals, constructs of perfect justice, which emphasize what people hold in common - rather than how peoples differ - as citizens of a global community" (Garcia, 1992:112-113). Lynch (1989:72) laat hom soos volg hieroor uit:

They [i.e. human rights] are normative statements about human life. They derive from the very existence of that life, they apply everywhere and to everyone, and are, thus the only universal body of moral guidance on the relationships of individuals, groups and nations, and internally within nations.

In bogenoemde aanhalings kom duidelik na vore dat die menseregte-ideologie 'n globale gedragskode daarstel. Skynbaar het die partikuliere morele oriëntasieraamwerke wat die gedrag tussen groepe en individue binne die primale en agrariese beskawingsvorme gereguleer het, en wat meestal godsdienstig gefundeer en sterk tradisiegebonde was, hul houkrag in 'n pluralistiese, globalistiese samelewingsverband verloor en is die globalistiese, sekulêre menseregte-ideologie (met sy humanistiese grondinstelling) in die plek daarvan gestel. In die globale maatskaplike ongewing geld menseregte, terwyl die partikuliere (godsdienstige) morele sisteme tot die vlak van die persoonlike lewe teruggedwing is.

Die vraag kan wel gevra word waarom die menseregte-ideologie in samehang met die opkoms van die globalistiese samelewing tot 'n globale ideologie ontwikkel 
Dre opkoms ran die menseregle-ideologie en enkele begeleidmgsimplikasies daarvan

het. Die antwoord moet miskien daarin gesoek word dat die opkoms van 'n ontwikkelde samelewingskonteks ons nie net tot 'n bestaan in 'n globalistiese samelewingsbestel gedoem het nie, maar ook kragte ontketen het wat die mens nie meer kan beheer nie en waarvoor nou op die globale vlak na oplossings gesoek word. Die ontwikkelde beskawing gaan onder 'n hele aantal krisisse gebuk, soos onder meer die energiekrisis, ongewingskrisis, die vraagstukke rondom wêreldvrede, die ontwikkelingsvraagstuk en talle krisisse op politieke, ekonomiese en sosiale gebied (Van Niekerk, 1992:136-180, 233-239). Menseregte vonn deel van die oplossingstrategie wat die radelose mens aanwend om hierdie krisisse en vraagstukke die hoof te bied:

The overarching message is that the struggle for human rights, democracy and environmentally sustainable development is a global one. It is not possible to support the aspiration to one without the other. All are indivisible for all human beings, and in these respects our future is a common one, or we do not have one (Lynch et al., 1992:11; vgl. Potgieter, 1989).

Van al die probleme is die vraagstuk van wêreldvrede sedert die Tweede Wêreldoorlog die vernaamste probleem wat deur middel van die menseregteideologie betrek word. Die VVO se Universele Deklarasie van Menseregte van 1948 het as belangrikste oogmerk die handhawing van wêreldvrede gehad. Die opkoms van die hedendaagse globalistiese orde het die vraagstuk van die wyse waarop die groot diversiteit wat daarin voorkom, gehanteer behoort te word ten einde steeds vrede te bewaar, na vore gebring. Die pluralistiese aard van die globalistiese samelewingsbestel kompliseer die vтedesvraagstuk. Etniese en kulturele pluralisme het op verskeie wyses in die geskiedenis beslag gekry, onder meer as gevolg van oorlog, imperialisme, bevolkingsverskuiwings en grensverskuiwings (Watson, 1992:244-245). Die opkoms van die moderne nasiestaat as politieke eenheid en veral die Europese imperialisme in die na-Renaissance tydperk het bygedra tot die opkoms van die pluralistiese aard van die hedendaagse globalistiese samelewingsverband. In hierdie verband is dit noodsaaklik om daarop te let dat pluralisme nie net op die globale vlak voorkom nie, maar dat dit ook binne nasiestate aanwysbaar is (Van Niekerk, 1995:67-70).

Nasiestate word ook met dieselfde problematiek van godsdienstige, taalmatige, etniese, sosiale, rasse- en klasseverskeidenheid gekonfronteer. Slegs $9 \%$ van vandag se nasiestate word deur 'n enkele elniese groep bewoon (Garcia, 1992:104). Meer mense het sedert die Tweede Wêreldoorlog in gewelddadige konflik binne nasiestate gesterf as in tussenstaatlike konflik (Van Niekerk, 1992:179). Daardeur word 'n enstige toets vir dic menseregte-ideologie met sy sterk klem op individuele regte aangelê. Met die totstandkoming van die Universele Deklarasie van Menseregte in 1948 wou die meeste regerings die minderheidsgroepe binne die grense van hul state assimileer. Hierdie pogings het 
meestal misluk, soos ook Afrika se nasiebou-fantasieë van die na-koloniale tydperk (Humphrey, 1988:36; Watson, 1992:241). Die opperste skynheiligheid met betrekking tot die handhawing van menseregte blyk egter steeds uit die wyse waarop die "klub" van regerings van nasiestate hul minderhede behandel. Dit maak inderdaad ' $n$ bespotting van pogings om deur middel van menseregte harmonie in die hedendaagse globale, pluralistiese samelewingsverband te handhaaf.

Die opkoms van 'n globalistiese wêreldorde het nie net meegehelp aan die opkoms van die menseregte-ideologie nie, maar die pluralistiese aard van die globale orde het hierdie globalistiese ideologie ook voor sy grootste dilemma te staan gebring.

\subsection{Die opkoms van 'n sekulêre samelewingsbestel}

Die menseregte-ideologie kan net inslag vind in 'n sekulêre klimaat waarin die mens self op 'n tipiese humanistiese wyse as uitgangspunt geneem word, en tot volle ontplooiing kom. Die sekulêre humanisme is tans die oorheersende lewensen wêreldbeskouing in die Westerse wêreld. Hierdie sekulêre klimaat is die resultaat van 'n historiese ontwikkelingsgang wat sedert die Renaissance in die Westerse wêreld plaasgevind het. Met die Renaissance kom die breuk met die teïstiese lewens- en wêreldbeskouing van die Middeleeue en kom 'n antroposentrisme in 'n toenemende mate na vore. As gevolg van sy wil tot die verklaring en beheersing van die werklikheid deur middel van die moderne wetenskap en tegniek en die gewaande magsgreep wat die mens daardeur op die werklikheid verkry (die idee van kennis is mag), het die mens homself verhef tot alleenheerser oor die werklikheid en selfbepaler van sy eie lot. Die moderne, ontwikkelde samelewingsbestel is 'n sekulêre bestel waarin die outonome mens die inisiatief in eie hande geneem het. Die opkomende sekularisasie na die Renaissance hang gevolglik ook saam met die opkomende ontwikkelde samelewingsbestel (Van Niekerk, 1992:281-285)

Sekularisasie lei tot die sekularisering van die mens se morele bewussyn en belewing. Die opkoms van die menseregte-ideologie in samehang met die toeneınende sekularisasie behels dat daar op sedelike gebied 'n verplasing kom vanaf die opvatting dat die mens 'n verpligting en verantwoordelikheid teenoor God en die medemens het, tot ' $n$ opvatting dat die mens natuurlike en inherente regte het. Die menseregte-ideologie is 'n huınanistiese ideologie waarin die sogenaamde regte van die mens in die inherente waardigheid van die menslike persoon gefundeer word (vgl. Potgieter, 1989, De Villiers et al., 1992:19; Hausermann, 1988:131). Die transformasie vanaf die Middeleeuse opvatting van verpligtinge en verantwoordelikhede na die moderne opvatting van menseregte, word raak saamgevat in die volgende woorde: 
Die opkoms van die menseregte-ideologie en enkele begeleidingsimplikasies daarvan

A common and useful way of describing the change from the medieval to the modern world is to say that the idea of duty gave way to the idea of right. It was certainly not the case, of course, that the idea of duty disappeared; it merely happened that instead of beginning with the structure of the creation and deducing the duties of man, thinkers took their initial bearings from man and derived the structure of the creation (Laqueur \& Rubin, 1979:5).

Uit die opkoms van die menseregte-ideologie blyk dit duidelik dat dit nie uit 'n godsdienstige instelling teenoor die menslike bestaan voortspruit nie (vgl. Potgieter, 1989). In hierdie verband kan die verwysings na God waar menseregte ter sprake is, misleidend voorkom. Deur die naam van God aan die regte van die mens te koppel poog opstellers van aktes en grondwette bloot oin op een van vele wyses sanksie aan menseregte verleen. Een so 'n voorbeeld kom voor in die Amerikaanse Declaration of Independence van 1776: "We hold these truths to be self-evident, that all men are created equal, that they are endowed by their Creator with certain unalienable Rights, that among these are Life, Liberty and the Persuit of Happiness" (Iwe, 1986:102-103). Hierdie woorde berus waarskynlik op 'n waninterpretasie van die Christendom. Die menswaardigheid van die mens is kragtens die Christelike godsdiens nie inherent in die mens self gesetel nie, maar daarin dat die mens skepsel van God is. Die mens is menswaardige wese omdat hy ondanks sy gevalle toestand en sondige natuur deur sy Skepper uit genade tot diens aan God en sy medemens geroep word ( $\mathrm{vgl}$ Potgieter, 1989; Strauss, 1988:12). Hierdie saak word skynbaar nie in menseregte-handveste verreken nie, aangesien hierdie handveste deur die sekulêre menseregte-ideologie onderlê word.

Die menseregte-ideologie is een van die tipiese master narratives van die modeme tyd wat moes meehelp on die groot versoening, vrede, gelykheid en eenheid in die wêreld teweeg te bring - 'n toestand wat ons na 'n ideale wêreldsamelewing sou lei (vgl. Potgieter, 1989). Net soos die natuurwetenskap en tegnologie die mens moes bevry van die onderworpenheid aan natuurkragte, so moes die demokrasie en die menseregte-ideologie die mens van onderworpenheid en onderdrukking op die sosiaal-politieke terrein bevry, soos reeds beweer is Die menseregte-ideologie verteenwoordig in 'n sekere sin die modernisme op die morele en sosiaal-politieke terrein, aangesien daardeur gepoog word om 'n sekulêre, globale ordening van gedrag teweeg te bring. Dié humanistiese regulering van die menslike denke en gedrag bring onder meer 'n ongesonde nivellering op die lewens- en wêreldbeskoulike terrein teweeg. 
E.J. van Niekerk

\section{Begeleidingsimplikasies van die menseregte-ideologie binne die Suid-Afrikaanse onderwyskonteks}

In hierdie afdeling word op grond van die voorafgaande uiteensetting gewys op enkele begeleidingsimplikasies van die menseregte-ideologie. Vanselfsprekend kan nie in besonderhede hierop ingegaan word nie. Die bedoeling is om enkele probleemareas uit te lig wat nie in die hedendaagse akademiese gesprek oor menseregte genoegsame aandag kry nie, en meestal ook nie in die juiste perspektief gestel word nie.

Eerstens 'n paar gedagtes oor die verband tussen die onderwys, ontwikkeling en die menseregte-ideologie. Die opkoms van die moderne skool as instelling van massa-onderwys hang ten nouste saam met die opkoms van die ontwikkelde samelewingsbestel (Van Niekerk, 1994). Die skool as instelling sosialiseer die jeug vir deelname aan die lewe in hierdie beskawingsverband. Die gesindhede, vaardighede en kennis on doeltreffend daarbinne te kan funksioneer word reeds op skoolvlak oorgedra. Die aandrang op gelykheid in die onderwys (as mensereg) hang saam met die idee dat alınal op 'n gelyke grondslag moet kan deel in die verneende voordele wat die ontwikkelde samelewingsverband gebring het (Van Niekerk, 1986:127-131, 180-185; Van Niekerk, 1992:288-293; RSA, 1995:17-20). Dit is egter baie duidelik dat nie alınal in die wêreld en in SuidAfrika oor die nodige/dieselfde beskawingsagtergrond en middele beskik om in 'n gelyke mate aan die ontwikkelde bestel deel te hê nie (vgl. Unesco, 1993). Die sogenaamde agtergeblewenes word soms selfs op 'n kunsmatige wyse bevoordeel (byvoorbeeld deur middel van ontwikkelingshulp) in 'n poging om hul daartoe te "bemagtig" (vgl. Van den Berg, 1991). In Suid-Afrika kan die beleid van regstellende aksie hiermee in verband gebring word. Die oorsaak vir die toestand van "agtergeblewenheid" word telkens elders as by die agtergeblewenes self gesoek, byvoorbeeld by Apartheid, want dit word nie as aanvaarbaar beskou dat nie almal daartoe in staat is om gelyk binne die ontwikkelde beskawingsverband te presteer nie (RSA, 1995:17-20; DE, 1995:15-28). Die onderwys word op hierdie wyse die slagveld waar die slag om toelating tot 'n bevoorregte posisie in die ontwikkelde samelewingsverband gelewer word.

Benewens die oogluikende beskawingsbotsing, hou hierdie stryd groot konflikpotensiaal en talle negatiewe/verswarende gevolge in 'n multikulturele, multilinguale en etnies plurale samelewingsverband vir die onderwys in. Die vernaamste hiervan word tans in Suid-Afrika in die vorm van 'n algemene standaardverlaging, die demoralisering van die onderwyserskorps en omgekeerde diskriminasie beleef. Ter wille van die nasiebou-ideaal en in 'n poging om "agtergeblewenes" op te hef teenoor diegene wat reeds binne die ontwikkelde beskawingskonteks presteer, word laasgenoemdes op allerlei wyses aan bande gelê. Hierin speel die menseregte-ideologie ook 'n rol. Die blote teenwoordig- 
Die opkoms van die menseregte-ideologie en enkele begeleidingsimplikasies daarvan

heid van aansienlike getalle van die sogenaamde agtergeblewe groepe in skole wat tradisioneel die meer ontwikkelde bevolkingsdeel gehuisves het, benadeel laasgenoemdes omdat daardeur 'n veelfasettige addisionele las op hierdie skole geplaas word ter wille van die nasiebou- en gelykheidsideaal. Binne 'n ontwikkelende samelewingskonteks met sowel 'n ontwikkelde as "agtergeblewe" komponent bestaan die verwagting skynbaar dat dit die ontwikkelde bevolkingsdeel se verantwoordelikheid is om die res op te hef met die noodwendige negatiewe gevolge wat dit vir die onderwys inhou

Die hele aangeleentheid van ontwikkeling en deel word van 'n ontwikkelde samelewingsbestel is baie kompleks en die gevolge van maatreëls om dit teweeg te bring is nie altyd voorspelbaar nie. Utopiese verwagtinge wat in hierdie verband van die onderwys gekoester word, wreek hul dikwels op diegene wat hierdie verwagtinge koester. 'n Bepaalde beskawingsagtergrond en kulturele ingesteldheid hang met ontwikkeling saam. Hierdie agtergrond en ingesteldheid ontwikkel nie oomag nie, selfs nie deur middel van die onderwys nie. Dit is wel so dat die opkoms van die menseregte-ideologie saamhang met die opkoms van die ontwikkelde beskawing, maar laasgenoemde kan nie deur middel van die toekenning van menseregte opgetower word nie. Teenswoordig word die voorsiening van basiese onderwys byvoorbeeld as 'n mensereg beskou. In baie ontwikkelende lande is hierdie mensereg egter problematies: eerstens omdat die middele tot die uitvoering daarvan ontbreek; tweedens omdat daar skynbaar wanpersepsies oor die rol van die onderwys in ontwikkeling bestaan. Onderwys speel wel 'n belangrike rol daarin, maar dit is beslis nie al faktor nie. Demokratisering en die menseregte-ideologie op sigself sal nie in Afrika ontwikkeling teweegbring nie. Oor die algemeen kan beweer word dat verwagtinge in hierdie verband gans te hoog en soms selfs misplaas is (Tedla, 1995; De Wet, 1996; Unesco, 1993; Van Niekerk, 1994; Fuller, 1991).

In Suid-Afrika met sy komplekse bevolkingsamestelling word menseregte aangegryp om verhoudinge tussen groepe en individue onderling te reel, ook in die onderwys. Daar is in die inleiding reeds beweer dat die verwagting bestaan dat die hele etos van die skool deur die menseregte-ideologie deursuur sal word, soos duidelik blyk uit Hoofstuk 7 van die Witskrif oor Onderwys en Opleiding (RSA, 1995). Die menseregte-ldeologie dien as saambindende waardesisteem vir die program van nasiebou in die naam van vrede, geregtigheid, voorspoed, ontwikkeling en eenheid. Soos in die globale konteks word ook in ons interafhanklike konteks gepoog om die sogenaamde reënboognasie in die naam van menseregte en die demokrasie te integreer. Ook hier sal die hantering van groepregte in die praktiese (onderwys-)situasie die menseregte-ideologie voor sy grootste toets te staan bring. Die beskawings-, kulturele en rassebotsings op kampusse en aan sekere skole, soos van tyd tot tyd in die pers gerapporteer, dui daarop dat die onderwys in hierdie verband 'n groot probleemarea is. Daar is al 
meermale deur die skrywer daarop gewys dat die opvoedende onderwys alleen sinvol beslag kan kry binne die konteks van 'n partikuliere godsdienstige, lewensopvatlike en kulturele raamwerk (Van Niekerk, 1991, 1992, 1995). Dit is sterk te betwyfel of die menseregte-ideologie enigsins sinvol hieraan in die praktyk kan help beslag gee.

Daar is in paragraaf 2.3 daarop gewys dat die menseregte-ideologie 'n sekulêre ideologie is wat in 'n sekulêre klimaat na vore getree het, en dat dit 'n ongesonde nivellering op die lewens- en wêreldbeskoulike terrein teweegbring. Op grond hiervan kan verwag word dat 'n onderwysstelsel wat deur hierdie ideologie deursuur en gerig word in ' $n$ toenemende mate aansluiting sal vind by die sekulêrhumanistiese grondinstelling van die menseregte-ideologie. Selfs godsdiensonderrig aan skole kan hierdeur geraak word.

\section{Slot}

Drie bydraende faktore tot die opkoms en vestiging van die menseregte-ideologie is in hierdie artikel bespreek. Na aanleiding hiervan is op enkele begeleidingsimplikasies van hierdie ideologie gewys. Vanweë die opkoms en vestiging van die ontwikkelde/ontwikkelende, globalistiese, sekulêre samelewingsbestel sal openbare onderwysinstellings waarskynlik in 'n toenemende mate 'n sekulêrhumanistiese karakter openbaar en afwyk van die ideale van Christelikgefundeerde opvoedende onderwys. Só gesien, word die kinders van die land benadeel deur die menseregte-wending in die onderwys.

\section{Bibliografie}

DAVIES, $\mathrm{P}$ ed. 1988. Human rights. London : Routledge.

DE (Department of Education). 1995. Report of the committee to review the organisation, governance and funding of schools. Pretoria : Department of Education

DE VILLIERS, B., VAN VUUREN, D J. \& WIECHERS, M. 1992. Human rights Documents that paved the way. Pretoria : HSRC

DE WET, C. 1996. Is onderwys in Suid-Afrika 'n spieëlbeeld van Afrika-onderwys? 'n Vergelykende studie van enkele gehalte-indikatore en -determinante. Referaat . OVSAkongres. Potchefstroom, 19 Januarie

FULLER, B 1991. Growing up modern The Western state builds Third-World schools New York Routledge

GARCIA, R L. 1992 Cultural diversity and minority rights: A consummation devoutly to be demurred (In Lynch. J., Modgil, C. \& Modgil, S., ed. Cultural diversity and the schools (vol 4). Human rights, education and global responsibilities London: The Falmer Press p 103-120.)

Grondwet van die Republiek van Suid-Afrika, No. 200 van 1993

HAUSERMANN, J. 1988 Myths and realities. (In Davies $P$, ed. Human rights London: Routledge p. 126-154)

HUMPHREY, J P. 1988 The Magna Canta of mankind. (In Davies, P., ed. Human rights. London Routledge p 31-39.)

IWE, N S S 1986 The history and contents of human rights. New York : Peter Lang

Koers 61(3) 1996:311-322 
Die opkoms van die menseregte-ideologie en enkele begeleidingsimplikasies daarvan

KING, E.W. 1992. Education for world awareness: Teaching strategies for worldmindedness. (In Lynch, J., Modgil, C \& Modgil, S, ed. Cultural diversity and the schools (vol. 4) Human rights, education and global responsibilities London: The Falmer Press p 229-240.)

LAQUEUR, W. \& RUBIN, B. 1979. The human rights reader. Philadelphia : Temple University Press

LEVIN, L 1988. The rights of the child (In Davies P., ed. Human rights. London : Routledge p 40-50.)

LYNCH, J. 1989. Multicultural education in a global society. London : The Falmer Press.

LYNCH, J., MODGIL, C. \& MODGIL, S., ed. 1992. Cultural diversity and the schools (vol 4). Human rights, education and global responsibilities London: The Falmer Press.

LYOTARD, J-F. 1987 (Vertaal deur C Janssen \& D Veerman) Het postmoderne uitgelegd aan onze kinderen. Kampen : Kok Agora

POTGIETER, J.M. 1989. Gedagtes oor die nie-Christelike aard van menseregte. Tydskrif vir Hedendaagse Romeins-Hollandse Reg, (52) 386-408.

PRETORIUS, F J. 1985. Ideologie en opvoeding: 'n metabletiese oopdekking Pretoria : Universiteit van Suid-Afrika. (D.Ed.-proefskrif.)

RSA. 1995 Witskrif oor onderwys en opleiding. Staatskoerant 163/3, 15 Maart 1995

STRAUSS, D.F.M 1988. Gereformeerde ekumeniese sinode (GES) oor menseregte. Roeping en Riglyne, 36(2): 10-12

TEDLA, E. 1995 Sankofa African thought and education. New York : Peter Lang

UNESCO. 1993. World education report. Paris : Unesco

VAN DEN BERG, J.H 1991. Pest syphilis aids. Over een metabletische oorzaak van pandemieën Nijkerk : Callenbach.

VAN NIEKERK, EJ 1986. Die revolusieverskynsel in die opvoedings- en opvoedkundewerklikheid. 'n Metableties-eksemplariese studie. Port Elizabeth : Universiteit van Port Elizabeth. (M Ed-verhandeling.)

VAN NIEKERK, E.J. 1991 'n Histories-pedagogiese perspektief op sedelik-religieuse opvoeding. (In Steyn, J.C red. Onderwys in transformasie: opstelle in die Historiese Opvoedkunde Stellenbosch : Universiteitsuitgewers en -Boekhandelaars. p. 30-65.)

VAN NIEKERK, E.J 1992 'n Temporaliteitspedagogiese ontleding en evaluering van die globaliseringsverskynsel. Pretoria : Universiteit van Suid-Afrika. (D.Ed.-proefskrif.)

VAN NIEKERK, E J. 1994. Key factors in the rise of mass popular education and their relevance for education in Southern Africa in the twenty first century. Conference paper: South African Comparative and History of Education Society. Gaborone, Botswana, 2527 October.

VAN NIEKERK, E.J 1995. Die globale konteks van multikulturele onderwys. Tydskrif vir Christelike wetenskap, 31(1 \& 2):66-80.

VISSER, P J. \& POTGIETER, J.M 1994 Enkele gedagtes oor skoolonderwys en die Grondwet. Regsmening voorgelê aan SAFSOS (SA Federasie van Staatsondersteunde Skole.) 19 November

WATSON, K. 1992. Ethnic and cultural diversity and educational policy in an international context ( $n$ Lynch, J., Modgil, C. \& Modgil, S., ed Cultural diversity and the schools (vol. 4) Human rights, education and global responsibilities. London : The Falmer Press. p. 241-269.)

WEISSBRODT, D. 1988 Human rights: An historical perspective. (In Davies P., ed. Human rights. London: Routledge. p. 1-20)

WRONKA, J.M. 1992. Human rights and social policy in the 21 st century. Maryland University Press of America 